\title{
Metazoan parasites of the small-spotted catshark (Scyliorhinus canicula, Linnaeus 1758) caught off the Mediterranean Sea
}

\author{
Gangemi Jessica $1{ }^{1}{ }^{*}$, Napoli Ettore ${ }^{2}$, Marino Fabio ${ }^{1}$ and Gaglio Gabriella ${ }^{2}$ \\ ${ }^{1}$ Department of Chemical, Biological, Pharmaceutical and Environmental Sciences, University of Messina, Italy. \\ 2 Department of Veterinary Sciences, University of Messina, Italy.
}

Publication history: Received on 17 December 2019; revised on 24 December 2019; accepted on 27 December 2019

Article DOI: https://doi.org/10.30574/gscarr.2019.1.2.0014

\begin{abstract}
Scyliorhinus canicula, also known as small-spotted catshark, is an elasmobranch worldwide distributed and in some areas of Mediterranean basin represents the most abundant elasmobranches species. This species is extensively fished and marketed throughout Europe, however despite its economic relevance, the conservation status, the biology and pathology of this elasmobranchs species are poorly investigated. Goal of this study was to investigate the metazoan fauna of $S$. canicula caught in the Mediterranean Sea. During the study period a total of 86 specimens of $S$. canicula were caught and examined. Of the 86 examined S. canicula, 81 (94.2\%) tested positive for parasites presence. Two parasitic taxa were identified, the nematode Proleptus obtusus (93\%) and the cestode Eutetrarhynchus ruficollis (2.3\%). The high prevalence of $P$. obtusus observed in the present study is similar to those observed in Ireland, United Kingdom and Spain. Noteworthy, for the first time the cestode E. ruficollis was retrieved in specimens of S. canicula.
\end{abstract}

Keywords: Nematode; Cestode; Scyliorhinus canicula; Proleptus obtusus; Eutetrarhynchus ruficollis; Mediterranean Sea.

\section{Introduction}

Scyliorhinus canicula (Linnaeus, 1758), also known as small-spotted catshark or dogfish, is an elasmobranch that populates temperate European waters and in particular all the coastal waters of eastern Atlantic and Mediterranean Sea, with the exception of the Dead Sea [1]. The small-spotted catshark is a small shark with a size that ranges between 20 and $60 \mathrm{~cm}$, although in some cases can reach one meter of length. The skin is rough, on the back is sand-colored with black and brown dots, while the belly is clear and uniform. This specie is oviparous and coupling occurs in deep waters from late summer to November; later the females return in shallow waters and spawn up to June-July. Each egg laid is enclosed within a cornea theca of about $5 \mathrm{~cm}$ in length. The hatchlings are already independent and don't receive any kind of parental care. Scyliorhinus canicula is carnivorous species and his diet consists in mollusks, cephalopods, crustaceans, worms and small fish.

The small-spotted catshark lives over sandy, gravelly or muddy bottoms at depths ranging from 150 to $300 \mathrm{~m}$ [2].

This species is widely distributed, and in some areas of Mediterranean basin represents the most abundant elasmobranch species [3]. Moreover, according to FAO statistics, this species is extensively fished and marketed throughout Europe and Italy is the fifth nation in the world to import sharks behind Spain, South Korea, China and Mexico [4]. In Italy the meat of this species is appreciated especially along the coast of Apulia and Sardinia. The catching occurs through bottom trawls and longlines [5]. However, the excessive fishing of small-spotted catshark, as well as of other sharks, has led to a massive reduction of the populations of these elasmobranchs, in fact, shark species diversity

\footnotetext{
${ }^{*}$ Corresponding author

E-mail address: jessysgt1990@yahoo.com
} 
in the Mediterranean area has dropped approximately 50\% in less than 50 years due to fishing pressure [6]. Therefore, deep-sealing monitoring activities are needed to assess and to improve the conservation status of this species. Scyliorhinus canicula is included in the red list of the International Union for Conservation of Nature [7] and classified as "least concern", therefore it is of the greatest importance to monitor the conservation status of this species. Nowadays, despite its economic relevance, the conservation status, the biology and pathology of this elasmobranch species are poorly investigated. Parasites are common finding in elasmobranch, as well as teleost fish [8], [9]; Parasitic species and their host are generally at equilibrium in aquatic organisms [10], however changes in the environment (natural such as, temperature and climate or anthropogenic, such as pollution and urbanization) can modify the state of balance between parasite, host and nature, thus resulting in disease [11]. Therefore, it is of the greatest importance to study the parasitic fauna of endangered wild species. Moreover, the characterization of the helminth fauna of edible aquatic organism is of considerable importance from the point of view of hygiene and public health. Unlucky, the investigations on the parasitic fauna of $S$. canicula are scant and dated. The parasites commonly reported are copepods, such as Albionella globose, localized in the skin, Lernaeopoda globose, affecting spiracles and nasal cavities [12] and Lernaeopoda galei commonly observed in cloacal area. Two monogeneous trematodes species, namely Hexabothrium appendiculatum and Leptocotyle minor has been described in the gills [13]. Finally, among nematodes has been described the presence of Proleptus obtusus, in the spiral valve intestine and stomach [14], and Anisakis simplex larvae in the stomach wall. The purpose of this study was to investigate the parasitic fauna in a large number of individuals from the fishing oceanographic campaigns carried out in the Mediterranean Sea.

\section{Material and methods}

\subsection{Sampling site and study population}

The small-spotted catsharks were caught, in November 2015, during five different oceanographic trawling experimental campaigns in the Ionian Sea. In particular, the sharks were caught in waters off the Portopalo di Capo Passero (36 $40^{\prime} 59^{\prime \prime}$ N, $15^{\circ} 08^{\prime} 53^{\prime \prime}$ E; Syracuse province, Sicily), were the seabed is sandy. The captures have been performed by the mean of trawling at a depth comprises from 60 and 80 meters.

\subsection{Laboratory procedure}

Specimens of $S$. canicula caught were transported to the laboratory in refrigerated containers. The sharks were identified by an alphanumeric code and were measured and weighed. The small-spotted catshark was classified as adult $(>30 \mathrm{~cm})$ or young $(\leq 30 \mathrm{~cm})$ based on the full body length, according to Olaso et al., 2004 [15].

The shark's skin, the gills and cloaca and inner nasal flaps were carefully checked for ectoparasites presence.

In order to detect the presence of internal parasites and the relative abundance a total worm count was performed. Briefly, the esophagus, the stomach and spiral valve intestine were extracted separately open and carefully inspected and the contents were collected according to anatomical sites, sieved to disperse gross food residues and placed in Petri dishes of $10 \mathrm{~cm}$ of diameter and observed under a stereomicroscope to collect the parasite.

\subsection{Parasites identification}

The collected parasites were washed in physiological solution and stored in vials containing alcohol 70\%, according to subjects and anatomical sites.

The parasites were classified at species level using morphological keys [16]. Moreover, in 10 specimens (5 males and 5 females) of identified parasitic species morphometric studies were performed.

\subsection{Statistical analysis}

The prevalence (P), mean intensity of infection (MI) and mean abundance (MA) were calculated based on the definitions presented by Bush et al.,1997 [17]. Chi-square test Yates corrected was performed to compare eventual differences in rate of parasitic infection between young and adult sharks. Differences with a $p$-value $<0.05$ were considered significant. All statistical analyses were performed using GraphPad Prism version 6.00 for Windows (GraphPad Software, San Diego California USA, www.graphpad.com). 


\section{Results}

During the study period a total of 86 specimens of $S$. canicula were caught and examined. The weight of dogfish ranged from 68 to 423 grams with an average of 259 grams. The length varied from 27 to $50 \mathrm{~cm}$ with an average of $42.1 \mathrm{~cm}$. The study population was composed by 9 young and 77 adult specimens. At the external examination any ectoparasite was observed, neither potential lesions associated to the presence of these noxae, however in some specimens (4 out of 86) skin lesions due to trauma from trawling were observed. Of the 86 examined S. canicula, 81 (94.2\%) tested positive for parasites presence. Two parasitic taxa were identified, in the $97.5 \%$ of the examined sharks (79/81) monospecific infections were observed, while only $2.5 \%$ of the cases (2/81) harboured two different species. The most retrieved species was the nematode Proleptus obtusus (Figures 1 ) in 80 subjects ( $\mathrm{P}=93 \%$ ), whit a mean abundance of 11.6 and a mean intensity of 12.5. The stomach is the most frequent site of infection of $P$. obtusus; 78 out of 80 positive specimens and a total of 850 parasites collected (mean abundance 9.9; mean intensity 10.7), of which were 289 males (mean intensity 4.4) and 561 females (mean intensity 7.7); while 38 sharks tested positive to P. obtusus presence in the spiral valve intestine and a total of 149 parasites were collected (mean abundance 3.9; mean intensity 1.7), of which were 46 males (mean intensity 1.6) and 103 females (mean intensity 2.7). Two specimens of S. canicula harboured (P = 2.3\%.) in the spiral valve intestine a cestode belonging to the species Eutetrarhynchus ruficollis (Figure 1). A total of 5 cestodes were collected with a mean abundance of 0.05 and a mean intensity of 2.5 .

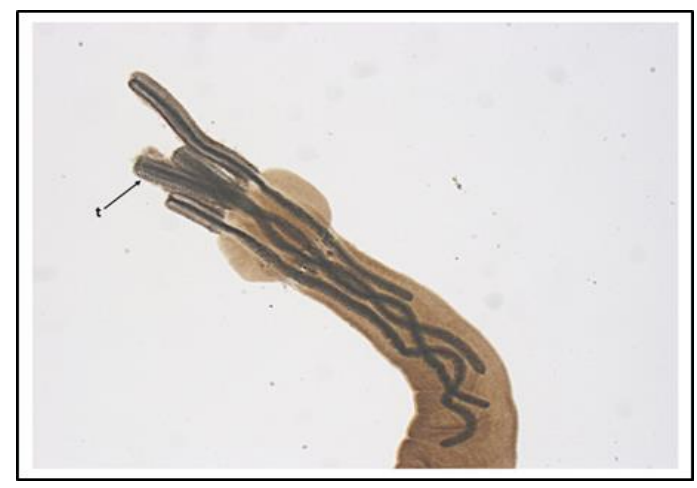

Figure 1 Eutetrarhynchus ruficollis, cephalic region; in the scolex it is possible to observe the four typical tentacles (t).

The morphometric studies were performed on 10 specimens of $P$. obtusus and on 5 specimens of E. ruficollis.

Proleptus obtusus presented a thick transversely striated cuticle and a rounded cephalic end.

The cuticle in the anterior end is inflated to form a peculiar cephalic collar (Fig.2a).

The body length of the male ranged from 24 to $25 \mathrm{~mm}$. The entire oesophagus measured from 112 to $150 \mathrm{~mm}$. Spicules unequal and dissimilar. Left spicule ranged from 1.3 to $1.8 \mathrm{~mm}$; right spicule ranged from 356 to $432 \mu \mathrm{m}$ and typically curved at right angle (Fig.2b).

The body length of the female ranged from 31.8 to $5.0 \mathrm{~mm}$. The oesophagus ranged from 4.2 to $6.3 \mathrm{~mm}$. The tail was conic with rounded tip (Fig.2c).

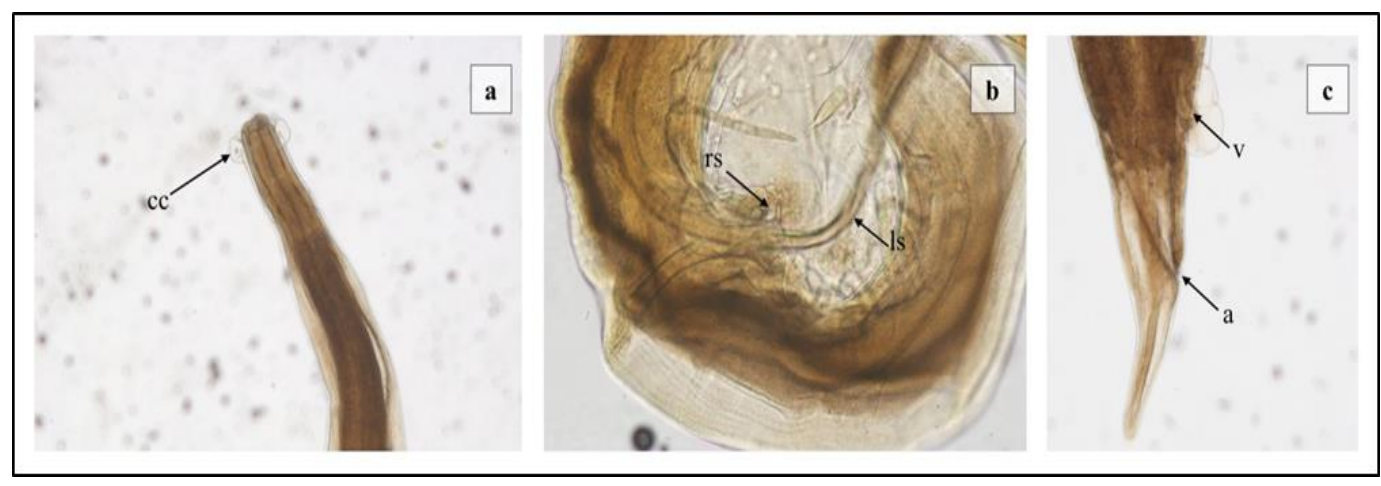


Figure 2 Proleptus obtusus. a) Cephalic region, the cuticle in the anterior end is inflated to form a peculiar cephalic collar (cc); b) Caudal end of $P$. obtusus male, left spicule (ls) and right spicule (rs) tipically curved at right angle; c) Caudal end of the P. obtusus female, vulva (v) and anus (a).

Eutetrarhynchus ruficollis (Fig. 1) was characterized by a long scolex and presented a length ranged from 10 to $15 \mathrm{~mm}$. The scolex presented two patelliform bothridia without margin and long tentacles. Armature typical eteroacanthous, principal rows abut single hook file at origin of half-spiral rows forming V's; at termination of rows on opposite face principal rows forming inverted V's. Proglottids slender and with marginal genital pore.

The Chi-square test was performed only for those specimens that horboured P. obtusus, due to the low prevalence observed for E. ruficollis, and any statistical significant differences was observed between young and adult sharks $(p=0.906854)$.

\section{Discussion}

The results herein reported add new informations to knowledges of the parasitic fauna of the small-spotted catshark of the Mediterranean basin.

Noteworthy, in contrast with other surveys conducted on S. canicula, any parasitic species was observed in the skin [17] or in the gills [12].

In $S$. canicula, two species belonging to the genus Proleptus were described, P. coronatus and more commonly P. obtusus [12]. Proleptus obtusus is a nematode commonly reported in the stomach and in the spiral valve of several elasmobranchs such as Scyliorhinus stellaris, S. canicula, Squalus acanthias, Scyllium catulus [18], Mustelus laevis, Gnathia panterina, Haploblepharus edwardsii [18] and Aetobatus narinari and races worldwide with different prevalence rates. In particular, in the small-spotted catshark the prevalence of $P$. obtusus ranges from 88.2\% [12] to 100\% [19], [20]. In the present study the prevalence of $P$. obtusus is $(\mathrm{P}=93 \%)$ similar to those observed in Ireland $(\mathrm{P}=88.2 \%$, Henderson \& Dunne, 1998; $\mathrm{P}=100 \%$, Casadevall et al. 2010), United Kingdom ( $\mathrm{P}=100 \%$, Moore, 2001) and $\mathrm{Spain}(\mathrm{P}=91.2 \%$, Sanmartin Duran et al., 1989; P=96.9\% Casadevall et al., 2010), however the mean intensity reported in this study (12.5) is sensibly lower to those observed in Spain [13], [19] and in Ireland [19].

In the specimens of $S$. canicula analysed in the present study, P. obtusus nematodes were observed in the stomach or in the spiral valve intestine or in both anatomic sites, and no difference in mean intensity was observed in the two anatomic localization sites. These findings are consistent with other surveys conducted on $S$. canicula [12]. The localization of $P$. obtusus is actually still not clear in fact, some authors observed P. obtusus only in the stomach of $S$. canicula (Moore, 2001) as observed in puffadder shyshark [18], conversely, others describe the presence of this parasite only at the level of the spiral valve intestine [22].

Interestingly, none of the sharks examined in this study showed anatomo-pathological lesions correlated to the presence of nematodes at the stomach and spiral valve intestine level; All the subjects examined presented a good health and nutrition status.

Noteworthy, any larva of Anisakidae was observed in the prevent survey, contrary to the similar studies conducted on parasitofauna of S. canicula [13], [12], [21], [20]. As concern cestodes, it is interesting to note that in this study was reported for the first time the presence of the cestode E. ruficollis in the small-spotted catshark. In fact, in this species the commonly cestodes reported are Crossobothrium longicolle and Nybelinia lingualis [21] or the larvae of Trypanorhyncha [22], while E. ruficollis is normally described in M. mustelus [23].

\section{Conclusion}

Studies on the composition of parasitic fauna of wild fish populations represent a useful tool for investigating many aspects of the ecology, biology and health status of and endangered species.

The data of this survey confirm the large presence the parasite P. obtusus in S. canicula and the role of this shark as definitive host as already indicated by others [13], [12], [21], [20]. 
Moreover, for the first time the presence of the cestode E. ruficollis was reported in S. canicula, however, further studies are needed to understand if the presence of E. ruficollis in the small-spotted catshark is an occasional finding or if this cestode is a normal character of the parasitofauna of $S$. canicula in the Mediterranean basin and could be used as biological marker since so far it has not been found in $S$. canicula caught in other geographical areas. ..

\section{Sitography}

https://www.graphpad.com/guides/prism/7/user-guide/index.htm?citing_graphpad_prism.htm

\section{Compliance with ethical standards}

\section{Acknowledgments}

I thank all the authors, in particular Professor Gabriella Gaglio for her valuable contribution in the identification of parasites.

\section{Disclosure of conflict of interest}

This research received no specific grant from funding agencies in the public, commercial or non-profit sectors.

\section{References}

[1] Blache J, Codenat J and Stanch J. (1970). Clés de determination des poisson de mer signalés dans l'Atlantique oriental tropical cente de 20 ème parallèle N. et le 15 èmeparallèle S. Faune tropicale ORSTOM, 18, 1-479.

[2] Stichez F. (1993). Las comunidades de peces de la plataforma de Cantàbrico. Publicaciones especiales instituto Espanol de oceanografia, 13, 137.

[3] Capapé C, Tomasini JA and Quignard JP. (2000). Les Elasmobranches Pleurotrêmes de la côte du Languedoc (France méridionale, Méditerranée septentrionale). Observations biologiques et démographiques. Vie et Milieu, $50(2), 123-133$.

[4] FAO Fisheries Department, Fishery Information, Data and Statistics Unit, Fishstat plus. Universal software for fishery statistical time series. Catches and landings 2004.

[5] Relini G, Bertrand J and Zamboni A. (1999). Synthesis of the Knowledge on bottom fishery resources in central Mediterranean (Italy and Corsica). Biologia Marina Mediterranea, 6(1), 868.

[6] Ferretti F, Myers RA, Sartor P and Serena F. (2005). Long term dynamics of the chondrichthyan fish community in the upper Tyrrhenian Sea. ICES CM Document, 25, 1-34.

[7] IUCN. (2017). The IUCN red list of threatened species.

[8] Marino F. (2006). Damage due to parasites in mediterranean teleosts. Parassitologia, 48, 18-21.

[9] Briguglio G, Di Caro G, Napoli E, Comignano F. Ferrantelli V, Gaglio G and Lanteri G. (2017). Metazoan parasites of the John Dory Zeus faber Linnaeus, 1758 collected from the Mediterranean Sea. Cahiers de Biologie Marine, 58, 83-89

[10] Marcogliese DJ. (2005). Parasites of the super- organism: Are they indicators of ecosystem health? International Journal of Parasitology, 35, 705-716.

[11] Iwanowicz DD. (2011). Overview on the effects of parasites on fish health. Report of Leetown Science Center, US Geological Survey.

[12] Henderson AC and Dunne JJ. (1998).The metazoan parasites of the lesser-spotted dogfish (Scyliorhinus canicula) from the Galway Bay area. Irish Naturalist's Journal, 26(3/4), 104-107.

[13] Sanmartin Duran ML, Quinteiro P and Ubeira FM. (1989). Nematode parasites of commercially important fish in NW Spain. Diseases of Aquatic Organisms, 7, 75-77.

[14] Skryabin KI, Shikhobalova NP, Schulz RS, Popova TI, Boev SN and Delyamure SL. (1194). Key to Parasitic Nematodes. vol. 3, E.J. BRILL, Koln. 
[15] Olaso I, Velasco F, Sánchez F, Serrano A, Rodríguez-Cabello C and Cendrero 0. (2005). Trophic Relations of LesserSpotted Catshark (Scyliorhinus canicula) and Blackmouth Catshark (Galeus melastomus) in the Cantabrian Sea. Journal of Northwest Atlantic Fishery Science, 35, 481-494.

[16] Bush AO, Lafferty KD, Lotz JM and Shostak AW. (1997). Parasitology meets ecology on its own terms: Margolis et al revisited. Journal of Parasitology, 83, 575-583.

[17] Leigh-Sharpe WH. (1918). Parasitic copepod of Scyllium canicula, Part I. Parasitology, 11, 29-34.

[18] Petter AJ and Radujković BM. (1989). Parasites des poissons marins du Montenegro: nematodes. Acta Adriatica, $30,195-236$.

[19] Moravec F, Van as JG and Dyková I. (2002). Proleptus obtusus Dujardin, 1845 (Nematoda: Physalopteridae) from the puffadder shyshark Haploblepharus edwardsii (Scyliorhinidae) from off South Africa. Systematic Parasitology, 53, 169-173.

[20] Casadevall M, Martinez M and King P. (2010). The lesser-spotted dogfish (Scyliorhinus canicula): parasites and scavenger habits. Rapport Commission International pour l'esploration scientifique de la Mér Mediterranée, 39, 470 .

[21] Moore ABM. (2001). Metazoan parasites of the lesser-spotted dogfish Scyliorhinus canicula and their potential as stock discrimination tools. Journal of the Marine Biological Association of the United Kingdom, 81, 1009-1013.

[22] Di Cave D, Orecchia P, Ortis M and Paggi L. (2003). Metazoan parasites from some elasmobranchs of thyrrenian sea. Biologia Marina Mediterranea, 10(2), 249-252.

[23] Radujkovic, B.M. and Sundic, D. (2014) Parasitic Flatworms (Platyhelminthes: Monogenea, Digenea, Cestoda) of Fishes from the Adriatic Sea. Natura Montenegrina, 13, 7-280.

\section{How to cite this article}

Gangemi J, Napoli E, Marino F and Gaglio G. (2019). Metazoan parasites of the small-spotted catshark (Scyliorhinus canicula, Linnaeus 1758) caught off the Mediterranean Sea. GSC Advanced Research and Reviews, 1(2), 10-15. 